Francke, A.L., Verkaik, R., Peeters, J.M., Spreeuwenberg, P., Lange, J. de, Pot, A.M. Dementia case management through the eyes of informal carers: a national evaluation study. Dementia: International Journal of Social Research and Practice: 2017, 16(5), 642-655

\begin{tabular}{|l|l|}
$\begin{array}{l}\text { Postprint } \\
\text { Version }\end{array}$ & 1.0 \\
\hline Journal website & http://dem.sagepub.com/content/early/2015/11/06/1471301215614165.long \\
\hline Pubmed link & $\underline{\text { http://www.ncbi.nlm.nih.gov/pubmed/26552856 }}$ \\
\hline DOI & $10.1177 / 1471301215614165$ \\
\hline
\end{tabular}

This is a NIVEL certified Post Print, more info at http://www.nivel.eu

\title{
Dementia case management through the eyes of informal carers. A national evaluation study
}

\author{
ANNEKE L FRANCKE RENATE VERKAIK, JOSE’’ M PEETERS AND PETER SPREEUWENBERG \\ JACOMINE DE LANGE ANNE MARGRIET POT
}

\begin{abstract}
This paper focuses on the evaluation of dementia case management in the Netherlands, as well as factors associated with positive evaluations of informal caregivers. A survey was completed by 554 informal carers. The majority of the informal carers were older (69\% was 55p), and female (73\%), and often concerned the partner or adult children of the person with dementia. Eighty percent indicated that the contact with the case manager facilitated their role as informal carer, while $95 \%$ or more stated that the case manager showed sufficient understanding, allowed enough space to decide together on how to approach problems in the care, took time to listen to their story, gave sufficient attention to and showed interest in their relative, took their schedule into account and/or kept appointments. Contrary to the expectations, multilevel analyses did not show association between informal caregivers' care burden and the evaluation of case management. Neither were the period living with dementia and the number of personal contacts with the case manager associated with the evaluations of informal caregivers. However, being the partner of the patient was significantly related $(\mathrm{p}<0.05)$ to a positive overall evaluation by informal carers. These results suggest that sufficient case management resources should be offered and targeted especially towards partners of people with dementia.
\end{abstract}

\section{INTRODUCTION}

People with dementia often face a lengthy and intensive care trajectory. For those living at home, much of the care falls to informal carers, such as partners or adult children. Almost all informal carers experience problems in caring for a relative with dementia: for instance, difficulties in dealing with behaviour changes and fears about admitting their relative to a nursing home (Zwaanswijk, Peeters, van Beek, Meerveld, \& Francke, 2013). In addition, informal carers often experience moderate to high-carer burden (Etters, Goodall, \& Harrison, 2008; Kurasawa et al., 2012), with feelings of overwhelming responsibility, difficulties combining work commitments with their role as carers, sleep disturbance and psychological problems (De Boer et 
Francke, A.L., Verkaik, R., Peeters, J.M., Spreeuwenberg, P., Lange, J. de, Pot, A.M. Dementia case management through the eyes of informal carers: a national evaluation study. Dementia: International Journal of Social Research and Practice: 2017, 16(5), 642-655

al., 2012; McCurry, Logsdon, Teri, \& Vitiello, 2007; Pot, van Dyck, \& Deeg, 1995). The burden of informal care at least partly explains why partners of people with dementia are four times more likely to suffer from depression than people whose partner does not have dementia (Joling et al., 2010). Previous research also indicates that most informal carers need information and advice, e.g. on how to cope with behavioural problems, the progression of the illness, emotional support and coordination of dementia care (e.g. Diehl-Schmid et al., 2013; Peeters, Van Beek, Meerveld, Spreeuwenberg, \& Francke, 2010). Professional support may be required to meet the information and support needs of informal carers. Therefore, new approaches, such as case management, are on the rise in developed countries. In this paper, we define case management in dementia as the provision by a professional of coordinated treatment, care and support to people with dementia who are living at home and to their informal carers, over the entire trajectory from first symptoms or diagnosis up to admission to a care facility or death (Dutch National Dementia Care Standard, 2012).

Satisfaction with case management is often high (De Lange \& Pot, 2007; Minkman et al., 2009), and some studies have also shown positive effects on clinical outcomes (Callahan et al., 2006; Vickrey et al., 2006). However, studies on the effects or evaluations of case management have produced varying results (e.g. Reilly et al., 2015; Somme et al., 2012). For instance, in a previous Dutch study, evaluations of the care provided were no better in the group who received case management services than in the care-as-usual group (Jansen, 2007; Jansen et al., 2011). One of the explanations given in that study was that case management had been offered at the very early stages of the illness when informal carers had not yet experienced a significant care burden. Furthermore, results of a systematic review on case management in dementia by Somme et al. (2012) suggested that outcomes and evaluations of case management interventions may be influenced by the frequency of contacts with the case manager.

The aim of this paper is to give insight into informal carers' evaluations of case management in dementia in the Netherlands, and the factors associated with positive evaluations. The main research questions addressed are as follows: (1) (a) How do informal carers of people with dementia rate the support from their case manager? (b) which aspects of case management are evaluated most positively and which aspects less positively? (2) Is the extent to which informal carers are positive about the case manager related to (a) a relatively high-perceived care burden? (b) a relatively long period living with the dementia diagnosis of the relative? (c) a relatively high number of personal (face-toface) contacts between informal carers and the case manager? (3) Which other characteristics of the informal carer (e.g. the family relationship) and the person with dementia are related to a positive evaluation of case management?

\section{METHODS}

Description of the setting and case management provision The study was performed within 13 regional networks for dementia care, forming a convenience sample of a total of 70 regional dementia care networks in the Netherlands.

The 13 participating networks signed up for the study, after an open call by the researchers and the Dutch Alzheimer Society. 
Francke, A.L., Verkaik, R., Peeters, J.M., Spreeuwenberg, P., Lange, J. de, Pot, A.M. Dementia case management through the eyes of informal carers: a national evaluation study. Dementia: International Journal of Social Research and Practice: 2017, 16(5), 642-655

The networks were spread over the country and concerned formal regional alliances of inpatient and outpatient care providers (e.g. home care organizations, nursing homes, elderly care homes, GPs and mental health centres). Providing case management to people with dementia and their informal carers was a key aspect of the work of the dementia care networks.

Table 1 provides an overview of main characteristics of our convenience sample compared with the total group of regional dementia care networks in the Netherlands. The total group characteristics are derived from a national inventory of Peeters, Francke, and Pot (2011), where contact persons of 52 of the total of about 70 networks completed questionnaire on the characteristics of their regional network. As Table 1 shows that the 13 participating networks in the current study do not differ much with the total group of networks, except for the length of history of case management.

\section{[TABLE 1]}

Table 1 also shows that seven of the participating networks only provided case management after a formal diagnosis of dementia has been made, whereas in the other six networks, case management was also available at the pre-diagnosis stage. However, the same general approach was taken by case managers across all networks: the case manager (trained as a nurse or social worker, and specialized in dementia care) acted as central person guiding the patient and family through the care process. The case manager provided information about dementia and options for professional support, and gave practical and family support, until admission to a nursing home or other facility or until the death of the patient. Face-to-face contacts (mainly at home) were often combined with email or telephone contacts. The frequency of contacts with the case manager was tailored and largely guided by the needs expressed by the individuals with dementia and their informal carers.

\section{Recruitment and sample of informal carers}

All informal carers who had just started to receive case management within one of the 13 participating networks were eligible for inclusion. From January to November 2010, about 900 eligible informal carers were asked via their case manager to participate in the study; 648 (72\%) gave permission for the case manager to pass on their name and address to the research team. These informal carers were sent a survey questionnaire at the start of the case management (T1). Informal carers sent back the completed surveys by postal mail to the researchers of NIVEL (Netherlands Institute for Health Services Research).

The T1-questionnaire was completed by 554 informal carers ( $85 \%$ response). The same 554 carers received a survey questionnaire one year later (T2); 429 of the group of 554 completed and returned the T2-questionnaire (77\% response).

\section{Variables and instruments}

To evaluate case management from the perspective of informal carers (see research question 1), the T2 survey questionnaire contained: . the 'Satisfaction with case management' questionnaire. The content validity, comprehensibility and internal consistency (Cronbach's alpha1/4.94) of this Dutch language questionnaire was previously tested and established by De Lange and Pot (2007). The questionnaire consists of 18 statements which are presented in Table 4, where the respondent has to indicate for each statement whether (s)he agrees (response categories: 'yes', 'no' and 
Francke, A.L., Verkaik, R., Peeters, J.M., Spreeuwenberg, P., Lange, J. de, Pot, A.M. Dementia case management through the eyes of informal carers: a national evaluation study. Dementia: International Journal of Social Research and Practice: 2017, 16(5), 642-655

'not applicable'). Furthermore, the questionnaire consists of a final question 'The case manager would like to receive an evaluation score from you. Please choose a score between 1 and 10' (11/4the worst score and 101/4the best score).

The following variables and instruments were used to determine which factors are associated with a positive or negative evaluation (see research questions 2 and 3): . 'self-perceived informal care burden', measured with the EDIZ, a 9-item Dutch language Rasch scale with satisfactory validity and reliability (Pot, Deeg, van Dyck, \& Jonker,1998; Pot et al., 1995). Earlier research (Pot et al., 1995) revealed that care burden measured with the EDIZ assesses one dimension from lower to higher care burden. The EDIZ was included in both the T1 and T2 questionnaires, but for this paper, where 'care burden' was designated as an independent variable, only data from the EDIZ at T1 were used (at T2 care burden might already be influenced by the delivery of case management, and therefore making use of T2 data as independent variable would be not appropriate); . the number of personal contacts with the case manager in the preceding year, which was asked in the questionnaire completed at T2; . background characteristics of the person with dementia (e.g. how long prior to T2 had the diagnosis of dementia been made) and background characteristics of the informal carers (e.g. relationship to the person with dementia). Tables 2 and 3 present all the assembled background characteristics.

\section{Analysis}

Descriptive statistics (frequencies and percentages) were used to answer research question 1, with the statistical package STATA. In addition, multilevel regression modelling, with the statistical package MLwiN, was used to answer research questions 2 and 3. We chose multilevel techniques (Snijders \& Bosker, 2012) because respondents are 'nested' within the regional networks. The informal carers' overall evaluation score of their case manager

\section{[TABLE 2]}

\section{[TABLE 3]}

(one of the items on the 'Satisfaction with the case manager questionnaire') was set as the dependent variable.

The multilevel analyses were executed in three steps. First, the effect of the informal carers' 'self-perceived care burden' on the dependant variable (i.e. the evaluation score) was analysed. Second, the length of the period between T2 and the point at which the formal diagnosis was made was added to the model. Third, the number of personal contacts between the informal carer and the case manager were included. Background characteristics of the informal carer and the person with dementia, as well as characteristics of the informal care provided were added to the model in the fourth and final step. The steps were cumulative; existing variables remained in the model with each new step. Using this approach, we were able to see whether the 'perceived care burden' changed with the addition of other independent variables. All independent variables included in the optimal model are presented in Table 5. Based on our finding in the multilevel analyses that partners more often provided a positive overall evaluation score (see section 'Factors related to a positive overall evaluation score'), we also used a Chi-square test to determine whether the 
Francke, A.L., Verkaik, R., Peeters, J.M., Spreeuwenberg, P., Lange, J. de, Pot, A.M. Dementia case management through the eyes of informal carers: a national evaluation study. Dementia: International Journal of Social Research and Practice: 2017, 16(5), 642-655

evaluations of specific aspects of the support from the case manager were different when evaluated by partners versus other informal carers.

\section{Ethical considerations}

Along with the questionnaire all respondents received an information letter explaining the aim of the study and stating that study participation (i.e. completion of the survey questionnaire) was completely voluntary. Completing and returning the questionnaire was considered as consent for participation. The questionnaire data were stored and analysed anonymously, in accordance with the Dutch act on protection of personal data (http://

www.privacy.nl/uploads/guide_for_controller_ministry_justice.pdf).

Further ethical approval of this study was not required under the applicable national Dutch legislation (http://www.ccmo.nl/en/), since all respondents were competent individuals and this survey study did not involve any interventions or treatments.

\section{RESULTS}

\section{Characteristics of the informal carers}

Of the 429 informal carers who completed the T2-questionnaire, $263(61 \%)$ indicated that they were still receiving case management support. The remaining 166 informal carers $(39 \%)$ no longer received case management because the person with dementia had passed away ( $n^{1 / 436)}$, or had been admitted to a nursing home $\left(\mathrm{n}^{1 / 478)}\right.$ or to another facility for people with dementia $\left(\mathrm{n}^{1 / 434)}\right)$. The majority of the informal carers were older (69\% was $55 \mathrm{p})$ female $(73 \%)$ and were often the partner or adult children of the person with dementia.

They often provided informal care several times a week (e.g. involving personal, domestic and/or psychosocial care; see Table 2).

Most of the respondents (59\%) had between two and six personal (face-to-face) contacts with the case manager during the first year of case management. However, there was wide variation in the number of personal contacts: a small number (4\%) had no personal contact with the case manager at all, while others had 13 or more contacts (see Table 2).

\section{Characteristics of the persons with dementia}

Most of the relatives with dementia were older females (65p) (see Table 3). At T2 (one year after case management began), 9\% of the informal carers stated that no formal dementia diagnosis had been made yet, although their relative had symptoms of dementia. In most cases (60\%), the diagnosis had been made between one and three years previously.

\section{Informal carers' evaluations of the case manager}

Informal carers were also asked to evaluate several aspects of the support from the case manager. Almost all aspects of case management received positive evaluations (Table 4). For example, the large majority if the informal carers (95\% or more) stated that the case manager showed sufficient understanding of their feelings, allowed enough space to decide together on how to approach problems in the care for the relative with dementia, took the time to listen to their story, gave sufficient attention to and showed interest in the relative with dementia, took their schedule into account when making an appointment and/or kept appointments. Looking at the content of 
Francke, A.L., Verkaik, R., Peeters, J.M., Spreeuwenberg, P., Lange, J. de, Pot, A.M. Dementia case management through the eyes of informal carers: a national evaluation study. Dementia: International Journal of Social Research and Practice: 2017, 16(5), 642-655

those items, we see that these items mainly concern the attention and empathy shown by the case manager.

A smaller percentage of informal carers (although still 80\%) were positive about the sufficiency of the information on the likely course of the illness and/or on whether the contact with the case manager had made it easier for them to continue to provide care for the person with dementia.

\section{[TABLE 4]}

In addition, Table 4 also shows that some of the informal carers had no experience with certain aspects of case management such as coordination of care and support in making difficult decisions (indicated by the number of respondents who filled-in 'not applicable'). Significant differences were found between partners of the person with dementia and other informal carers (mainly adult daughters of the person suffering from dementia) regarding how they experienced the following aspects of the support from the case manager (the numbers below correspond to the numbers listed in Table 4).

3. The case manager's advice about the best way to handle my relative was sufficient for me: $93 \%$ of partners versus $81.4 \%$ of other informal carers ( $\mathrm{p}^{1 / 40.02)}$.

5 . The contact with the case manager made it easier for me to continue the care: $89.5 \%$ of partners versus $71.1 \%$ of other informal carers $\left(\mathrm{p}^{1 / 40.00)}\right.$.

7. The contact with the case manager was, in my opinion, warm and empathetic:

$97.2 \%$ of partners versus $88 \%$ of other informal carers $\left(\mathrm{p}^{1 / 40.01}\right)$.

12. The case manager took the time to listen to my story: $90 \%$ of partners versus $94 \%$ of other informal carers $\left(\mathrm{p}^{1 / 40.01)}\right.$ ).

13. The case manager understood my needs: $96.9 \%$ of partners versus $88.3 \%$ of other informal carers $\left(\mathrm{p}^{1 / 40.03)}\right.$.

15. The case manager took my schedule into account when making an appointment: $100 \%$ of partners versus $92.6 \%$ of other informal carers $\left(\mathrm{p}^{1 / 40.01)}\right.$.

18. I felt supported by the case manager whenever I had to make a difficult decision regarding the care for my relative with dementia: $94.2 \%$ of partners versus $82.6 \%$ of other informal carers $\left(\mathrm{p}^{1 / 40.03}\right)$.

This list shows that partners are more often positive about the various aspects of the support provided by the case manager with the exception of Statement 12.

\section{Overall evaluation score}

Informal carers were also requested to choose an overall evaluation score for the case manager. The average rating was 8.0, on a scale of 1 (worst score) to 10 (best score). Only 5\% (n $1 / 418)$ of all informal carers gave the case manager a rating of 5 or lower; some explained this by noting that they had hardly any contact with the case manager due to illness, while others reported no added value compared with regular care. On average partners gave a higher overall evaluation score of 8.3, compared with other informal caregivers who gave an average overall score of 7.6.

Comments made by informal carers explaining positive evaluation scores were: . 'My contact with the case manager is outstanding'.

. 'Good appointments. I organize a lot by myself, I can always ring her if needed'.

. 'Our experience with the case manager is very positive. She organized everything, listened to us'.

- 'I am very satisfied with the case manager! Together with the home care and the day care it is going well'. 
Francke, A.L., Verkaik, R., Peeters, J.M., Spreeuwenberg, P., Lange, J. de, Pot, A.M. Dementia case management through the eyes of informal carers: a national evaluation study. Dementia: International Journal of Social Research and Practice: 2017, 16(5), 642-655

- 'I have received strong support from the case manager. I am very grateful!' . 'It was a great relief that I could ring whenever I did not know how to solve a problem'. . 'The case manager was a great support to us. It enabled us to keep my father at home'.

\section{[TABLE 5]}

\section{Factors related to a positive overall evaluation score}

Using multilevel regression analyses, we also analysed which characteristics were related to a more positive overall evaluation score. Contrary to our expectations, no significant multivariate associations were found between a higher perceived care burden, a longer period living with a dementia diagnosis or a higher number of contacts with the case manager on the one hand and a more positive evaluation score on the other hand (see Table 5).

In the final step of the multilevel modelling, we also took account of the background characteristics of the informal carers and the relatives with dementia. Only the family relationship between the informal carers and the person with dementia was significantly related to the evaluation of case management: informal carers who were partners of the person with dementia had higher odds of a positive evaluation $(\mathrm{p}<0.05)$.

\section{DISCUSSION}

\section{Main findings and reflections}

In general, informal carers evaluated case management positively and gave the case manager an average overall rating of 8 , on a scale of 1 to 10 . Ninety-five percent or more were positive about aspects of case management involving the attention and empathy of the case manager.

A significantly lower percentage of informal carers (80\%) were positive about the sufficiency of the information on the likely course of the illness and/or whether the case manager had made it easier for them to continue providing informal care. It is remarkable that the latter aspects of case management were less often positively appraised than other aspects, since information about the consequences of the illness and support for informal carers to facilitate the continued provision of care are core elements of case management (Verkade et al., 2010). Therefore, we recommend that case managers focus more on these elements. We also recommend future research into what information may be lacking on the progression of the illness and what kind of extra support is needed to help carers continue to provide informal care.

We also found that being the partner of the person with dementia (rather than another family member, friend or neighbour) was the only factor in the multilevel analyses that was significantly related to a more positive overall evaluation of the case manager by informal carers. We did not find evidence for the assumed relationship between a higher care burden, a longer period living with dementia and the number of personal contacts with the case manager on the one hand and a positive evaluation by informal carers on the other. This was somewhat surprising, considering that such a relationship was found in the meta-analyses by Somme et al. (2012). However, we must take account of the fact that we do not know how many mail or telephone contacts there were. It seems plausible that knowing that the case manager is basically always available when problems or questions arise strongly contributes to 
Francke, A.L., Verkaik, R., Peeters, J.M., Spreeuwenberg, P., Lange, J. de, Pot, A.M. Dementia case management through the eyes of informal carers: a national evaluation study. Dementia: International Journal of Social Research and Practice: 2017, 16(5), 642-655

the positive evaluations by the informal carer, irrespective of length or severity of care burden or number of contacts. Our study had a naturalistic design and focused on the evaluation of case management as currently implemented. In the Netherlands, dementia care networks decided to standardize case management not entirely, but to adapt their supply to individual needs of patients and informal caregivers. This 'tailored', nonstandardized approach means that there is variation in the kind of support given by the case manager and in the number of case management contacts. Such a tailored approach might better meet the needs of individuals, and might also be cheaper than a standard approach, since some clients will be satisfied with having a case manager available to call when they need advice.

\section{Strengths and limitations}

An advantage of our naturalistic design is that it is consistent with variations in common case management practice in the Netherlands. A disadvantage is that not all items measured are applicable in every case management situation, which explains the relatively large numbers of respondents who indicated that specific items of the 'Satisfaction with case management' questionnaire were not applicable (N/A). We used this questionnaire because it was at the time of investigation the only validated instrument in the Dutch language about satisfaction with dementia case management. But the instrument does not allow for degrees of satisfaction, and there is no room for neutral feelings. Moreover, the patient's perspective is not addressed. We, therefore, recommend future qualitative interviews with both informal caregivers and patients to further explore experiences with case management.

The strength of this study is that we performed multilevel analyses for testing associations between specific background characteristics (such as the family relationship with the person with dementia) and the evaluation scores of the informal carers. One of the explanations as to why the results of existing studies on case management are not unanimous may be that differences in the characteristics of informal carers are not always taken into account (Pimouguet, Lavaud, Dartigues, \& Helmer, 2010).

However, a limitation of the present study is that the case management evaluated was provided by a convenience sample of regional dementia care networks that signed up for the study after an open call. These networks have on average a relatively long history with case management and may therefore offer relatively high-quality case management.

Therefore, the high percentage of positive evaluations by informal carers cannot be automatically generalized to informal carers who use case management in other regions in the Netherlands or abroad. Still, we do not expect differences in other regional care networks with regard to the finding that partners provide the most positive evaluations of the case manager.

\section{CONCLUSIONS}

To conclude, informal carers in our study are generally positive about the support provided by case managers working in Dutch regional dementia care networks. Nevertheless, there may be room for improvement on certain core elements of case management: namely, giving sufficient information about what can be expected to happen during the course of the illness and providing support that enables the informal carer to continue in their care role. Case management appears to be most frequently appreciated by informal carers who are the partner of the person with 
Francke, A.L., Verkaik, R., Peeters, J.M., Spreeuwenberg, P., Lange, J. de, Pot, A.M. Dementia case management through the eyes of informal carers: a national evaluation study. Dementia: International Journal of Social Research and Practice: 2017, 16(5), 642-655

dementia. Since many partners still live with the dementia sufferer and are often old and vulnerable themselves, their support needs may be greater than those of other informal carers. This may also explain why they give the most positive evaluations. These results suggest that sufficient case management resources should be offered and targeted especially towards partners of people with dementia.

\section{Acknowledgements}

We thank ZonMw-NPO (the National Care for the Elderly Programme of the Netherlands Organisation for Health Research and Development) for funding this study.

\section{Declaration of Conflicting Interests}

The authors declared no potential conflicts of interest with respect to the research, authorship, and/or publication of this article.

\section{Funding}

The authors received no financial support for the research, authorship, and/or publication of this article.

\section{Authors' contributions}

ALF, JdL and AMP were responsible for the design of this study. ALF, JP and PS performed the analyses, advised by RV, JdL and AMP. RV and ALF drafted this manuscript in cooperation with JdL, JP, AMP and PS.

\section{REFERENCES}

Callahan, C. M., Boustani, M. A., Unverzagt, F. W., Austrom, M. G., Damush, T. M., Perkins, A. J., ... Hendrie, H. C. (2006). Effectiveness of collaborative care for older adults with Alzheimer disease in primary care: A randomized controlled trial. JAMA, 295, 2148-2157.

Callahan, C. M., Boustani, M. A., Unverzagt, F. W., Austrom, M. G., Damush, T. M., De Boer, A. H., ... Pot, A. M. (2102). Self perceived burden from informal care: Construction of the EDIZ-plus. Tijdschr Gerontol Geriatr, 43, 77-88.

De Boer, A. H., Oudijk, D., Timmermans, J. M., \& Pot, A. M. (2012). Self perceived burden from informal care: construction of the EDIZ-plus. Tijdschr Gerontol Geriatr [Journal of Gerontology and Geriatrics], 43, 77-88.

De Lange, J., \& Pot, A. M. (2007). Meetinstrument tevredenheid mantelzorgers bij case management. Verslag van de ontwikkeling en toetsing [Measurement instrument satisfaction of informal carers with case management. Report of the development and testing process]. Utrecht, The Netherlands: Trimbos-instituut.

Diehl-Schmid, J., Schmidt, E. M., Nunnemann, S., Riedl, L., Kurz, A., Fo" rstl, H., ... Cramer, B. (2013). Caregiver burden and needs in frontotemporal dementia. Journal of Geriatric Psychiatry Neurology, 26, 221-229. doi:10.1177/0891988713498467

Dutch Dementia Care Standard. (2012). Utrecht/Bunnik: Vilans/Alzheimer Nederland.

Etters, L., Goodall, D., \& Harrison, B. E. (2008). Caregiver burden among dementia patient caregivers: A review of the literature. Journal of the American Academy of Nurse Practitioners, 20, 423-428. doi:10.1111/j.1745-7599.2008.00342.x

Jansen, A. P. D. (2007). Effectiveness of case management among older adults with dementia symptoms and their informal carers (PhD thesis). Vu University, Amsterdam. Retrieved from http:// dare.ubvu.vu.nl/bitstream/handle/1871/13240/1 cover.pdf;jsessionid1/4079FC777C1BA74B0 BF02 775C05BD1912?sequence $1 / 41$

Jansen, A. P., van Hout, H. P., Nijpels, G., Rijmen, F., Dro“ es, R. M., Pot, A. M., ... van Marwijk, $\mathrm{H}$. 
Francke, A.L., Verkaik, R., Peeters, J.M., Spreeuwenberg, P., Lange, J. de, Pot, A.M. Dementia case management through the eyes of informal carers: a national evaluation study. Dementia: International Journal of Social Research and Practice: 2017, 16(5), 642-655

W. (2011). Effectiveness of case management among older adults with early symptoms of dementia and their primary informal caregivers: A randomized clinical trial. International Journal of Nursing Studies, 8, 933-943. doi:10.1016/j.jinurstu.2011.02.004

Joling, K. J., van Hout, H. P., Schellevis, F. G., van der Horst, H. E., Scheltens, P., Knol, D. L., ... van Marwijk, H. W. (2010). Incidence of depression and anxiety in the spouses of patients with dementia: A naturalistic cohort study of recorded morbidity with a 6-year follow-up. The American Journal of Geriatric Psychiatry, 18, 146-153. doi:10.1097/JGP.0b013e3181bf9fof

Kurasawa, S., Yoshimasu, K., Washio, M., Fukumoto, J., Takemura, S., Yokoi, K., .. . Miyashita, K. (2012). Factors influencing caregivers' burden among family caregivers and institutionalization of in-home elderly people cared for by family caregivers. Environmental Health and Preventive Medicine, 17, 474-483. doi:10.1007/s12199-012-0276-8

McCurry, S. M., Logsdon, R. G., Teri, L., \& Vitiello, M. V. (2007). Sleep disturbances in caregivers of persons with dementia: Contributing factors and treatment implications. Sleep Medicine Reviews, 11, 143-153.

Minkman, M. M., Ligthart, S. A., \& Huijsman, R. (2009). Integrated dementia care in the Netherlands: A multiple case study of case management programmes. Health \& Social Care in the Community, 17, 485-494.

Peeters, J. M., Francke, A. L., \& Pot, A. M. (2011). Organisatie en invulling van casemanagement dementie in Nederland. [Organization and content of dementia case management in the Netherlands]. Utrecht, The Netherlands: NIVEL.

Peeters, J. M., Van Beek, A. P., Meerveld, J. H., Spreeuwenberg, P. M., \& Francke, A. L. (2010). Informal caregivers of persons with dementia, their use of and needs for specific professional support: A survey of the National Dementia Programme. BMC Nursing, 7, 19. doi:10.1186/1472- 6955-9-9

Pimouguet, C., Lavaud, T., Dartigues, J. F., \& Helmer, C. (2010). Dementia case management effectiveness on health care costs and resource utilization: A systematic review of randomized controlled trials. The Journal of Nutrition Health and Aging, 14, 669676.

Pot, A. M., Deeg, D. J., van Dyck, R., \& Jonker, C. (1998). Psychological distress of caregivers: The mediator effect of caregiving appraisal. Patient Education and Counselling, 34, 43-51.

Pot, A. M., van Dyck, R., \& Deeg, D. J. (1995). Ervaren druk door informele zorg; constructie van een schaal [Perceived stress caused by informal caregiving. Construction of a scale]. Tijdschr Gerontol Geriatr, 26, 214-219.

Reilly, S., Miranda-Castillo, C., Malouf, R., Hoe, J., Toot, S., Challis, D., ... Orrell, M. (2015). Case management approaches to home support for people with dementia. Cochrane Database of Systematic Reviews, 1, CD008345.

Snijders, T. A. B., \& Bosker, R. J. (2012). Multilevel analysis: An introduction to basic and advanced multilevel modeling (2nd ed.). London, England: Sage Publishers.

Somme, D., Trouve, H., Drame' , M., Gagnon, D., Couturier, Y., \& Saint-Jean, O. (2012). Analysis of case management programs for patients with dementia: A systematic review. Alzheimers \& Dementia, 8, 426-436. doi:10.1016/j.jalz.2011.06.004

Verkade, P. J., van Meijel, B., Brink, C., van Os-Medendorp, H., Koekkoek, B., \& Francke, A. L. (2010). Delphi research exploring essential components and preconditions for case management in people with dementia. BMC Geriatric, 9, 54. doi:10.1186/1471-2318-10-54

Vickrey, B. G., Mittman, B. S., Connor, K. I., Pearson, M. L., Della Penna, R. D., Ganiats, T. G., ... Lee, M. (2006). The effect of a disease management intervention on quality and outcomes of dementia care: A randomized, controlled trial. Annals of Internal Medicine, 145, 713-726.

Zwaanswijk, M., Peeters, J. M., van Beek, A. P., Meerveld, J. H., \& Francke, A. L. (2013). Informal caregivers of people with dementia: Problems, needs and support in the initial stage and in subsequent stages of dementia: A questionnaire survey. The Open Nursing Journal, 7, 6-13. doi:10.2174/1874434601307010006 
Francke, A.L., Verkaik, R., Peeters, J.M., Spreeuwenberg, P., Lange, J. de, Pot, A.M. Dementia case management through the eyes of informal carers: a national evaluation study. Dementia: International Journal of Social Research and Practice: 2017, 16(5), 642-655

\section{TABLES}

Table I. Characteristics of the regional dementia care networks (sample versus total group of networks).

\begin{tabular}{lcc}
\hline Available supply of case management service & $\begin{array}{l}\text { Sample } \\
(n=13)(\%)\end{array}$ & $\begin{array}{l}\text { Total group } \\
(n=56)(\%)\end{array}$ \\
\hline Available from first dementia symptoms & 54 & 52 \\
Only available after formal diagnosis & 46 & 48 \\
Main tasks of case managers employed within the network & 100 & 100 \\
Practical support of clients and informal carers & 100 & 100 \\
Provision of information and advises & 100 & 95 \\
Multidisciplinary consultations & 100 & 89 \\
Assessments of clients' care needs & 92 & 87 \\
Family conversations & & 7 \\
Length of the network's experience with case management & 8 & 16 \\
Start in period I 995 up to 2000 & 23 & 77 \\
Start in period 200I up to-2005 & 69 & \\
Start after 2006 & & \\
\hline
\end{tabular}


Francke, A.L., Verkaik, R., Peeters, J.M., Spreeuwenberg, P., Lange, J. de, Pot, A.M. Dementia case management through the eyes of informal carers: a national evaluation study. Dementia:

Table 2. Characteristics of the informal carers $(n=429)$.

Sex of the informal carer

Male

Female

$73 \%$

Age

$<55$

$31 \%$

55-75

$41 \%$

75 or $>$

$28 \%$

Average age (range)

Relationship to the person with dementia

Partner

$56 \%$

Adult daughter or son (in law)

$39 \%$

Brother/sister/other family member

$1 \%$

Friend or neighbour

$4 \%$

Provision of informal care (number of times)

Daily

3 to 6 times a week

I to 2 times a week

$17 \%$

$<$ than once a week

$5 \%$

$<$ than once a month

Type of informal care (more than I type possible)

Personal (physical) care

Domestic care

Psychosocial support 
Francke, A.L., Verkaik, R., Peeters, J.M., Spreeuwenberg, P., Lange, J. de, Pot, A.M. Dementia case management through the eyes of informal carers: a national evaluation study. Dementia: International Journal of Social Research and Practice: 2017, 16(5), 642-655

Table 3. Characteristics of the persons with dementia $(n=429)$ one year after beginning case management.

Sex

Male $42 \%$

Female $58 \%$

Age

45-65 years

$1 \%$

$65-85$ years

$81 \%$

$85+$ years

$18 \%$

Average age (range)

80.9 (years)

(53-99)

Dementia diagnosis made?

No formal diagnosis yet, despite dementia symptoms

Yes, $<$ I year ago

$18 \%$

Yes, between I and 3 years ago

$60 \%$

Yes, 3-5 years ago

$10 \%$

More than 5 years ago

$3 \%$

Co-morbidity (various types of co-morbidity are possible)

Co-morbidity - at least one additional physical illness $\quad 44 \%$

Co-morbidity - at least one additional psychiatric illness $\quad 12 \%$

Co-morbidity - at least one additional sensory disability $27 \%$

No co-morbidity

$41 \%$ 
Francke, A.L., Verkaik, R., Peeters, J.M., Spreeuwenberg, P., Lange, J. de, Pot, A.M. Dementia case management through the eyes of informal carers: a national evaluation study. Dementia: International Journal of Social Research and Practice: 2017, 16(5), 642-655

Table 4. Evaluations of informal carers $(n=429)$ regarding support by case manager.

\begin{tabular}{|c|c|c|c|}
\hline & Yes $^{2}(\%)$ & No $(\%)$ & Not applicable ${ }^{a}(n)$ \\
\hline $\begin{array}{l}\text { I. The case manager has informed us sufficiently about the } \\
\text { resources available locally for the support of people } \\
\text { with dementia and their relative }\end{array}$ & 89 & 11 & 35 \\
\hline $\begin{array}{l}\text { 2. We were informed sufficiently about what can be } \\
\text { expected to happen during the course of the illness }\end{array}$ & 80 & 20 & 35 \\
\hline $\begin{array}{l}\text { 3. The case manager's advice about the best way to handle } \\
\text { my relative was sufficient for me }\end{array}$ & 83 & 17 & 43 \\
\hline $\begin{array}{l}\text { 4. The case manager offered me and/or my relative } \\
\text { sufficient help to accept support }\end{array}$ & 88 & 12 & 71 \\
\hline $\begin{array}{l}\text { 5. The contact with the case manager made it easier for } \\
\text { me to continue the care }\end{array}$ & 80 & 20 & 78 \\
\hline $\begin{array}{l}\text { 6. I could always contact the case manager for my } \\
\text { questions }\end{array}$ & 94 & 6 & 22 \\
\hline $\begin{array}{l}\text { 7. The contact with the case manager was, in my opinion, } \\
\text { warm and empathetic }\end{array}$ & 93 & 7 & 24 \\
\hline $\begin{array}{l}\text { 8. My case manager showed sufficient understanding for } \\
\text { my feelings }\end{array}$ & 95 & 5 & 36 \\
\hline $\begin{array}{l}\text { 9. I trusted the case manager to seek a solution together } \\
\text { with me, if ever things got too much for me. }\end{array}$ & 93 & 7 & 47 \\
\hline $\begin{array}{l}\text { 10. The case manager gave me sufficient opportunity for } \\
\text { joint decision-making about how to address the } \\
\text { problems in the care for my relative with dementia }\end{array}$ & 95 & 5 & 58 \\
\hline $\begin{array}{l}\text { II. The case manager gave my relative with dementia } \\
\text { sufficient opportunity for joint decision-making about } \\
\text { how to address the problems }\end{array}$ & 91 & 9 & 97 \\
\hline 12. The case manager took the time to listen to my story & 98 & 2 & 31 \\
\hline 13. The case manager understood what my needs were & 93 & 7 & 67 \\
\hline $\begin{array}{l}\text { 14. The case manager had sufficient attention for and } \\
\text { interest in my relative }\end{array}$ & 96 & 4 & 26 \\
\hline $\begin{array}{l}\text { 15. The case manager took my schedule into account when } \\
\text { making an appointment }\end{array}$ & 97 & 3 & 53 \\
\hline 16. The case manager adhered to the appointments & 95 & 5 & 22 \\
\hline $\begin{array}{l}\text { 17. The case manager adequately coordinated the help I } \\
\text { received from different people and organisations }\end{array}$ & 85 & 15 & 147 \\
\hline $\begin{array}{l}\text { 18. I felt supported by the case manager whenever I had to } \\
\text { make a difficult decision regarding the care for my } \\
\text { relative with dementia. }\end{array}$ & 88 & 12 & 134 \\
\hline
\end{tabular}

'In calculating the percentages 'yes' and 'no', we have not included the people who have filled-in 'not applicable' for the specific item. 
Francke, A.L., Verkaik, R., Peeters, J.M., Spreeuwenberg, P., Lange, J. de, Pot, A.M. Dementia case management through the eyes of informal carers: a national evaluation study. Dementia: International Journal of Social Research and Practice: 2017, 16(5), 642-655

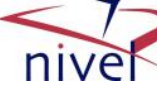

Table 5. The relationship between characteristics of informal carers, persons with dementia and the informal care provided, and the evaluation of case management by the informal carers.

\begin{tabular}{lcl}
\hline Parameter & Estimate & SE (U) \\
\hline Constant & 2.394 & 0.6391 \\
Perceived care burden & 0.03433 & 0.01888 \\
Diagnosis made less than two years ago or no formal diagnosis yet & -0.05796 & 0.115 \\
Diagnosis made two years ago or more & -0.04953 & 0.1275 \\
Number of contacts with case manager & 0.0253 & 0.03161 \\
Background characteristics of informal carer & & \\
Age & 0.003732 & 0.008784 \\
Being a partner of a person with dementia* & $-1.469 *$ & $0.2545^{*}$ \\
Sex & -0.03692 & 0.1013 \\
Health & -0.01629 & 0.05417 \\
Background characteristics of person with dementia & & \\
Age & 0.0007827 & 0.009894 \\
Co-morbidity; additional physical illness & 0.02454 & 0.03386 \\
Co-morbidity; additional psychiatric illness & & 0.09433 \\
Co-morbidity; additional sensory disability & -0.1235 & 0.07061 \\
Receives informal care from others too (other than the respondent) & -0.08341 & 0.06073 \\
\hline
\end{tabular}

${ }^{*} p<0.05$. 